\title{
Genetic Transformation of Durum Wheat (Triticum durum Desf.) through Particle Bombardment of Scutellar Tissues
}

\author{
Shigeo TAKUMI* and Takiko SHIMADA \\ Research Institute of Agricultural Resources, Ishikawa Agricultural College, Nonoichi, Ishikawa 921, Japan
}

Received 8 May 1997; accepted 1 September 1997

\begin{abstract}
This is the first report of the production of transgenic durum wheat. A transformation system for common wheat through particle bombardment of scutellar tissues of immature embryos was successfully applied to emmer wheat. Three emmer wheats, Triticum durum var. reichenbachii, T. durum var. agricunum and T. aethiopicum Jakubz., were used in the transformation experiments. The scutellar tissues isolated from immature seeds were bombarded with a plasmid, pDM302 containing the bialaphos-resistant gene (bar) under control of the rice actin 1 gene $(A c t 1)$ promoter. In $T$. durum var. agricunum, 25 bialaphos-resistant plants were independently regenerated from each green-spotted calli. On the other hand, no bialaphosresistant plants were recovered from the other two emmer wheat, T. durum var. reichenbachii and $T$. aethiopicum. Most regenerated plants grew into mature and fertile plants. The integration and inheritance of the bar gene were confirmed by the PCR amplification and Southern analysis in $T_{0}$ and $T_{1}$ plants. All 25 plants showed the positive band of the bar gene. The frequency of transformation was $1.17 \%$ (25 independent transformants/2144 immature embryos).
\end{abstract}

\section{Introduction}

Both Triticum durum Desf. and T. aethiopicum Jakubz., relative species to common wheat ( $T$. aestivum L.), are classified into emmer wheat $(2 n=4 x=$ 28, genome constitution $\mathrm{AABB}$ ) and belong to the tetraploid group; T. durum is one of the most important monocotyledonous crops as a raw material of pasta products. Of all wheats, $T$. durum is the second in importance after the common wheat $(2 n=6 x=$ 42, genome constitution AABBDD) [1]. However, genetic transformation in emmer wheats has not yet been reported.

The microprojectile bombardment system is a powerful technique for the genetic transformation of common wheat. The scutellar tissues of immature embryos have been successfully used as a target to deliver a foreign DNA through particle bombardment in common wheat [2-6]. In durum wheat, Bennici et al. [7] studied the callus formation of immature, 9- to 21-day-old, embryos and plant regeneration of the calli. The genotypic effects on immature embryo culture were reported in durum wheat [8]. He et al. [8] noted that six cultivars of $T$. durum formed embryogenic callus from scutellar tissues of immature

\footnotetext{
* Pesent address: Department of Biological and Environmental Science, Faculty of Agriculture, Kobe University, Nada-ku, Kobe 657, Japan
}

embryos at the induction frequency of $44 \%$ to $89 \%$, but no embryogenic calli were induced from epiblast tissues. Culture conditions also affected the callus induction and plant regeneration. Among four cultivars of durum wheat, the culture condition of immature embryos has been recently optimized using Murashige-Skoog [9] medium [10]. Moreover, immature embryos of durum wheat were cultured for callus induction on Linsmaier-Skoog (LS) medium [11] containing $2 \mathrm{mg} / l$ 2,4-dichlorophenoxyacetic acid (2,4-D) and $30 \mathrm{~g} / l$ sucrose, and for plant regeneration on a phytohormone-free LS medium [12]. These conditions for immature embryo culture are similar to our conditions for common wheat [6]. Immature embryos seemed to be the most appropriate explants for plant regeneration from callus cultures in durum wheat [12] and to produce transgenic plants of durum wheat by the microprojectile bombardment system. Here, we report the successful production of transgenic plants in durum wheat by the same method as in common wheat [6].

\section{Materials and Methods}

\section{1 Plant materials and culture of immature embryos}

Immature embryos of six durum wheat accessions were used to estimate the ability of green-spot formation. These durum wheats were grown in a greenhouse in Ishikawa, Japan. Immature seeds sterilized 
in $70 \%$ ethanol for $5 \mathrm{~min}$. and immature embryos isolated were placed with scutellar tissues exposed on the LS medium containing $2 \mathrm{mg} / \mathrm{l}$ 2,4-dichlorophenoxyacetic acid (2,4-D) and $0.25 \%(\mathrm{w} / \mathrm{v})$ Gelrite (Merck). Immature embryos of three emmer wheats ( $T$. durum var. reichenbachii, T. durum var. agricunum and T. aethiopicum Jakubz.) were used to examine the integration of a marker gene.

\section{2 Plasmid DNAs}

The plasmids $\mathrm{p} A c t 1-\mathrm{F}$ and $\mathrm{pDM} 302$ were used. $\mathrm{p}$ Act1-F [13] includes the gus coding region

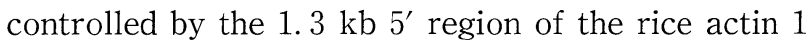
gene (Act1). pDM302 contains the bar (phosphinothricin acetyltransferase) gene placed after the rice Act1 promoter [14] as a selectable marker gene. The rice Act1 promoter showed high activity of transient gus expression in wheat cultured cells [15] and scutellar tissues [6]. Recombinant plasmids were amplified in liquid cultures of Escherichia coli, isolated by alkaline lysis, and purified twice by $\mathrm{CsCl}$-density centrifugation [16].

\section{3 Particle bombardment, selection of transfor- mants and enzyme assay}

Plasmid DNAs were adsorbed to gold particles (1.6 $\mu \mathrm{m}$ diam.) according to the protocol for the Biolistic ${ }^{\mathrm{R}}$ PDS-1000/He Particle Delivery System (Bio-Rad) and delivered to the target embryo tissues [15]. Immature embryos were transferred to selection medium comprised of LS medium containing $2 \mathrm{mg} / \mathrm{l} 2$, $4-\mathrm{D}$ and $5 \mathrm{mg} / l$ bialaphos two days after bombardment. After about 1 month, the bialaphos-resistant tissues were transferred to 2,4-D free LS medium containing $4 \mathrm{mg} / l$ bialaphos for regeneration. Following bombardment, immature embryos were incubated at $26^{\circ} \mathrm{C}$ for two days prior to the assay for GUS activity. GUS activity was histochemically assessed as described previously [15]. The numbers of blue spots showing transient gus expression per embryo were counted in two separate experiments. In each experiment, more than 20 immature embryos were used.

\section{4 Molecular analysis}

Plant genomic DNA was extracted from leaf tissues $(0.5$ to $1 \mathrm{~g})$ according to the minipreparation procedures of Mettler [17]), as modified by Liu et al. [18]. One primer set (BAR7 and BAR8) was synthesized based on the bar sequence to use for the primary PCR amplification. BAR7 and BAR8 are 5'-GATCCATGAGCCCAGAACGAC- $3^{\prime}$ and 5'-TTGCGGGTATGCCAGTTGAGT-3', respectively. Thirty cycles of PCR were performed in a programmed temperature control system (PC700, Astec). A single cycle of the primary PCR amplification consisted of the following steps; denaturation at $94^{\circ} \mathrm{C}$ for $1 \mathrm{~min}$., annealing at $57^{\circ} \mathrm{C}$ for $1 \mathrm{~min}$., and DNA synthesis at $72^{\circ} \mathrm{C}$ for $1 \mathrm{~min}$. Other conditions were described previously [6]. For the secondary amplification using nested primers, another primer set (BAR5 and BAR6), which were designed and synthesized based on the sequence of the bar gene, were expected to produce a 402 bp product after PCR amplification[6]. In the nested PCR, one microliter of the primary PCR products was used as a template. Thirty cycles of PCR were performed, and a single cycle of the nested PCR consisted of the following steps; denaturation at $94^{\circ} \mathrm{C}$ for $1 \mathrm{~min}$., annealing at $60^{\circ} \mathrm{C}$ for $1 \mathrm{~min}$., and DNA synthesis at $72^{\circ} \mathrm{C}$ for $1 \mathrm{~min}$. Amplified DNAs were analyzed by $\mathrm{EtBr}$ staining after $1.8 \%$ agarose gel electrophoresis at $50 \mathrm{~V} . \mathrm{PCR}$ products after electrophoresis were transferred to nylon membrane (Hybond- $\mathrm{N}^{+}$, Amersham). The major fragments were identified by Southern hybridization against a probe of the bar gene using the ECL system (Amersham). Moreover, total DNAs $(20 \mu \mathrm{g})$ of transformants were digested by HindIII. The methods of electrophoresis, Southern blotting, hybridization with ${ }^{32} \mathrm{P}$-labelled probes, and autoradiography were the same as those reported by Liu et al. [18].

\section{5 Seed fertility}

Selfed seed fertility (\%) was estimated by the seed setting rate of the first and second florets of ten spikelets in two to three ears per plant. Non-transformed plants were used as controls.

\section{Results and Discussion}

\section{1 Immature embryo culture}

In common wheat, He et al. [8] proposed a classification based on the five morphological stages of embryo development and concluded that the suitable stages for induction of scutellum callus were stages I, II, and III (about 10-16 days after anthesis). In most of the genotypes used in this study, the developmental stage III of embryo was observed 13 to 15 days after anthesis. Calli were induced from all the genotypes and the frequencies in most genotypes were as high as $100 \%$. Most calli derived from scutellar tissues at the suitable stages exhibit localized chlorophyll synthesis (green spots) with occasional formation of many green shoots [19]. However, the frequency of green-spot formation varied from $18.5 \%$ to $92.1 \%$ (Table 1) and markedly differed with the genotype. Similar results have been reported in a study using randomly chosen 35 cultivars of T. aestivum and six cultivars of T. durum [8] and in other studies using eight genotypes of $T$. aestivum 
Table 1.

Variation in callus induction and plant regeneration from immature embryos of durum wheats.

\begin{tabular}{lccc}
\hline \multicolumn{1}{c}{ Accession } & $\begin{array}{c}\text { Direct Germination } \\
(\%)\end{array}$ & $\begin{array}{c}\text { Callus Induction } \\
(\%)\end{array}$ & $\begin{array}{c}\text { Green Spot } \\
\text { Formation (\%) }\end{array}$ \\
\hline T. durum var. reichenbachii & 1.9 & 98.7 & 44.9 \\
T. durum var. agricunum & 0 & 100.0 & 92.1 \\
T. durum var. murciens & 0 & 100.0 & 27.8 \\
T. durum var. valenciae & 0 & 100.0 & 56.4 \\
T. durum var. affine & 0 & 100.0 & 88.9 \\
T. durum var. leucurum & 0 & 100.0 & 18.5 \\
\hline
\end{tabular}

Around 50 immature embryos were cultured on the LS medium containing $2 \mathrm{mg} / l$ 2,4-D.

Table 2 .

Culture response in four developmental stages of immature embryos from three emmer wheats.

\begin{tabular}{lcccc}
\multicolumn{1}{c}{ Accession } & \multicolumn{4}{c}{ Green spot formation (\%) } \\
& Stage I & Stage II & Stage III & Stage IV \\
\hline T. durum var. reichenbachii & 3.0 & 16.7 & 35.7 & 7.0 \\
T. durum var. agricunum & 11.8 & 78.4 & 91.9 & 84.2 \\
T. aethiopicum & 17.5 & 35.9 & 38.9 & 37.8 \\
\hline
\end{tabular}

The four developmental stages ( I -IV) were according to He et al. [8]. Around 50 immature embryos were cultured on the LS medium containing $2 \mathrm{mg} / l 2,4-\mathrm{D}$.

[20] and ten genotypes of T. aestivum [21]. Obvious$1 \mathrm{y}$, there is no correlation between callus induction and plant regeneration as suggested by Sági et al. [12]. T. durum var. agricunum showed the highest frequency of green-spot formation among the six genotypes. In common wheat, the importance of the developmental stage for embryogenesis has been reported with several explants including immature embryos [22]. In all three accessions of emmer wheat, the immature embryos in stage II and III formed green spots more efficiently than those in other stages (Table 2), which indicates that the suitable stage for induction of regenerable calli was stage II and III in emmer wheat.

\section{2 Transient expression of gus gene}

The scutellar tissues of wheat immature embryos (stage III) that had been cultured for one, five and nine days were bombarded with the particles coated with $\mathrm{p}$ Act1-F to estimate the transient expression. The rice Act1 promoter, which showed a high level of transient expression in cultured cells of durum wheat [15], efficiently yielded the transient gus expression in scutellar tissues of emmer wheat (Fig.1-a). The activity of the gus expression in the embryos of $T$. durum var. reichenbachii incubated for five days before bombardment was higher than that of the embryos incubated for one or nine days. The GUS activity of the embryos of the two other emmer wheat accessions incubated for nine days was slightly higher than that of the embryos incubated for five days. No clear correlation was recognized between the culture duration before bombardment and transient gus expression in any of the three emmer wheats (Fig. 2). T. durum var. agricunum gave the highest activity of transient gus expression.

\section{3 Selection and analysis of transformants}

The scutellar tissues of the immature embryos cultured for five days were bombarded with pDM302 to obtain the transgenic plants of three emmer wheats. Then, the cultured immature embryos were transferred to selection medium. After culture for about thirty days, some calli with green spots were observed. These green-spotted calli were transferred to regeneration medium containing $4 \mathrm{mg} / l$ bialaphos. In T. durum var. agricunum, 25 bialaphosresistant plants were independently regenerated from each of the green-spotted calli (Fig. 1-b). On the other hand, no bialaphos-resistant plants were recovered from the other two emmer wheats, $T$. durum var. reichenbachii and T. aethiopicum.

The integration of the bar gene in $\mathrm{T}_{0}$ bialaphosresistant plants was assessed by the combination of PCR amplification and Southern hybridization analysis. The nested PCR products from the plantlets integrating the bar gene showed the $402 \mathrm{bp}$ fragment, and the identity of the observed $402 \mathrm{bp}$ fragment was determined by Southern hybridization to the labelled bar gene. All 25 plants showed the positive band of the bar gene (Fig. 3). Most regenerated plants grew into mature plants (Fig. 1-c). The selfed seed fertility of 18 fertile transgenic plants varied from $60.0 \%$ to $90.7 \%$ (Fig. 4 ) and the average was $80.1 \%$. The fertility was lower in transgenic plants than in nontransformed plants, which may be due to the stress 

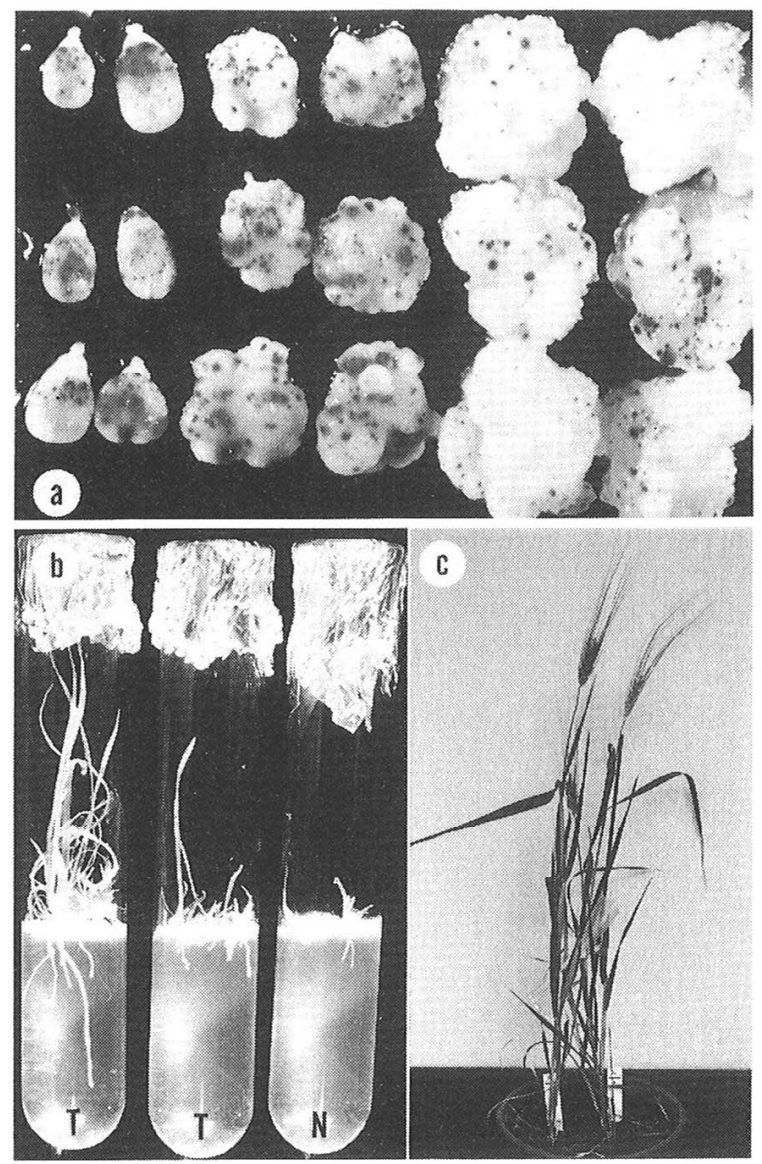

Fig. 1 (a) Transient gus expression in immature embryos of three emmer wheat accessions, T. durum var. reichenbachii (top), T. durum var. agricunum (middle) and $T$ aethiopicum (bottom).

These immature embryos were bombarded with $\mathrm{p} A c t$ I-F after one-day (left two), five-days (middle two) and nine-days (right two) incubation on LS medium containing $2 \mathrm{mg} / / 2,4-\mathrm{D}$ and then transformed cells (blue spots) were detected in in situ enzyme assay. (b) Regeneration of transformants on medium containing $5 \mathrm{mg} / l$ bialaphos in test tubes. $\mathrm{N}$, non-transformant as a negative control; T, transformed wheat plant. (c) Mature fertile transgenic durum wheats $\left(\mathrm{T}_{0}\right)$.

during the immature embryo culture.

The inheritance of the bar gene into $T_{1}$ progeny was tested by PCR amplification using two lines of transgenic plants. The $402 \mathrm{bp}$ fragment in the bar gene was detected in seven of nine $T_{1}$ plants from one transformant and in four of six from another. The bar gene was integrated and segregated in $T_{1}$ progenies, which suggested the inheritance of the transgene into the next generation. The total DNAs from five bar-positive $\mathrm{T}_{1}$ plants from one transformant were used for genomic Southern analysis. The Southern blot pattern is shown in Fig. 5. The frequency of transformation was $1.17 \%$ (25 independent transfromants/2144 immature embryos). In common wheat, the transformation frequency obtained by

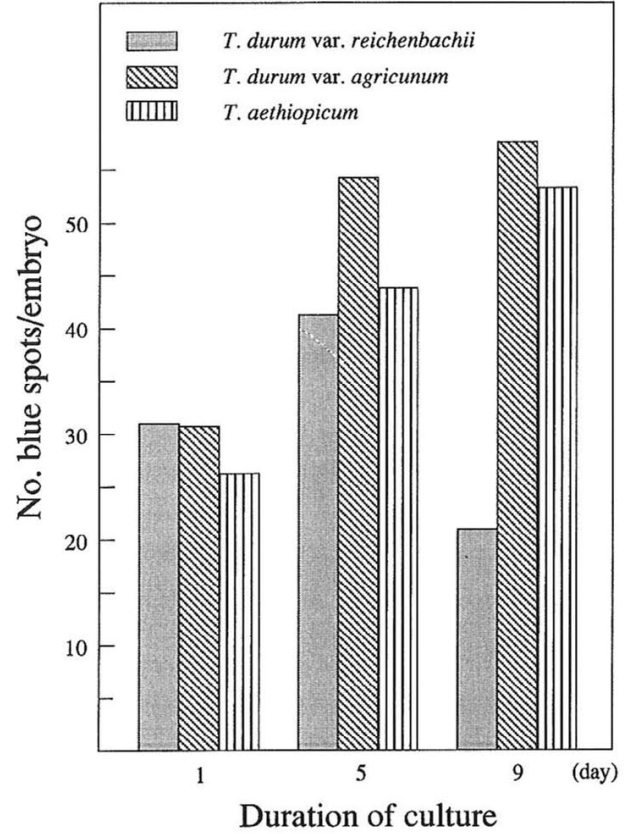

Fig. 2 Influence of the culture duration prior to bombardment on the transient gus expression in immature embryos of three emmer wheat accessions.

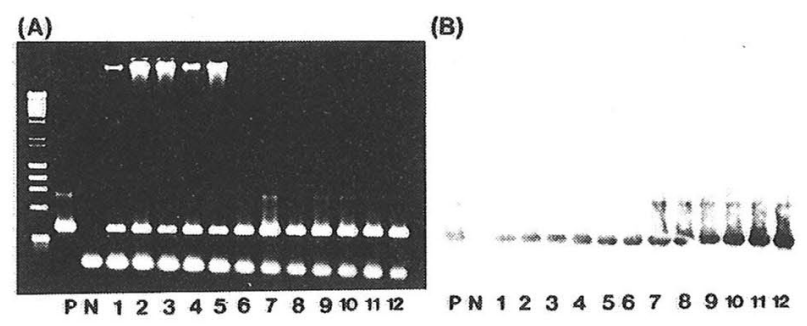

Fig. 3 (A) PCR amplification of the bar gene from total DN $\Lambda$ isolated from the bialaphos-resistant plants $\left(\mathrm{T}_{0}\right)$ of $T$. durum var. agricunum. EtBr staining pattern after agarose gel electrophoresis. Two primers recognized the bar gene and should amplify a 402 bp fragment. (B) Results of Southern hybridization after transfer of the DNA shown on the agarose gel of $(\mathrm{A})$.

$\mathrm{P}, \mathrm{pDM} 302$ as a positive control; $\mathrm{N}$, non-transformant as a negative control; lane 1-12, regenerated plants $\left(T_{0}\right)$.

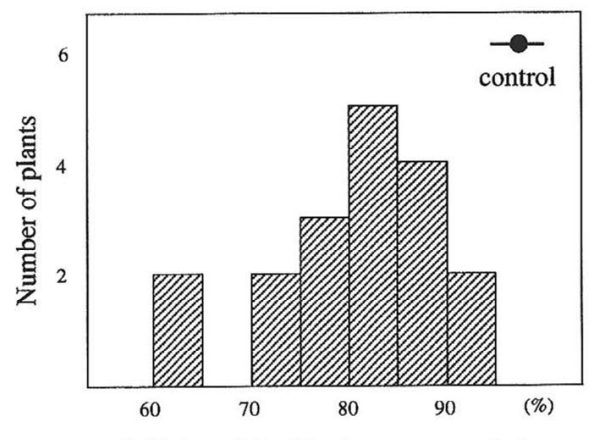

Selfed seed fertility in regenerated plants

Fig. 4 Selfed seed fertility (\%) of transgenic plants $\left(\mathrm{T}_{0}\right.$ generation) 


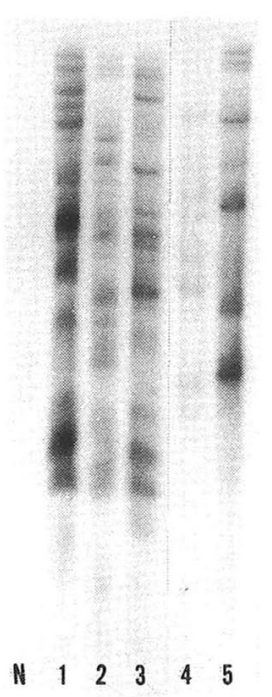

Fig. 5. Autoradiograms of Southern blots of bar-positive $\mathrm{T}_{1}$ plants from one transformant with the ${ }^{32} \mathrm{P}-$ labelled bar gene.

Each lane contains $20 \mu \mathrm{g}$ of total DNA. The used restriction emzyme was HindIII.

$\mathrm{N}$, non-transformant as a negative control; lane 15, bar-positive $\mathrm{T}_{1}$ plants.

Weeks et al. [2] and Nehra et al. [5] was about 1\%, which was similar to that we obtained in durum wheat.

Transgenic plants could be produced in durum wheat by the same method as in common wheat, and this procedure can be used as a routine system for gene transfer in durum wheat. However, several problems remain to be solved. First, transgenic plants were generated from $T$. durum var. agricunum, but not from other emmer wheats, which indicated that the genotypes from which transformants could be obtained were limited. No transformed plants were recovered in $T$. durum var. reichenbachii and $T$. aethiopicum, because their regeneration frequencies from cultured immature embryos were low. The efficient production of transgenic wheat plants requires the induction of green-spotted calli from more than $90 \%$ of immature embryos [23]. For the production of transgenic plants in these varieties, the in vitro culture system should be improved to increase the regeneration frequency markedly. Recently, Bommineni and Jauhar [10] generated the mature, fertile durum wheat plants from immature embryos of four durum wheat cultivars and they established an in vitro culture procedure for rapid regeneration. Second, the frequency of transformation was low. However, Nehra et al. [5] noted that the use of geneticin as a selection agent gave a higher transformation frequency in common wheat. Moreover, osmotic treatment of cultured immature embryos and improvement in the procedure used for culture and selection allowed increase of transformation frequency [24]. There- fore, transformed plants of durum wheat are expected to be more efficiently produced in future.

\section{Acknowledgements}

We are grateful to Dr. McElroy and Dr. R. Wu for the plasmids $\mathrm{p} A c t 1-\mathrm{F}$ and $\mathrm{pDM} 302$. We thank Meiji Seika Kaisha for the gift of bialaphos. We also thank Dr. K. Yamaguchi for his kind help.

\section{References}

[1] Bennici, A., 1986. In "Biotechnology in Agriculture and Forestry 2. Crops I." (ed. by Bajaj, Y. P. S.), p. 89-104, Springer-Verlag, Berlin, Heidelberg.

[2 ] Weeks, J. T., Anderson, O. D., Blechl, A. E., 1993. Plant Physiol., 102: 1077-1084.

[ 3 ] Vasil, V., Srivastava, V., Castillo, A. M., Fromm, M. E., Vasil, I. K., 1993. Bio/Technol., 11: 15531558.

[4] Becker, D., Brettschneider, R., Lörz, H., 1994. Plant J., 2: 299-307.

[5] Nehra, N. S., Chibbar, R. N., Leung, N., Caswell, K., Mallard, C., Steinhauer, L., Baga, M., Kartha, K. K., 1994. Plant J., 5: 285-297.

[6] Takumi, S., Shimada, T., 1996. J. Plant Physiol., 149: 418-423.

[ 7 ] Bennici, A., Caffaro, L., Dameri, R. M., Gastaldo, P., Profumo, P., 1988. Euphytica, 39: 255-263.

[8] He, D. G., Yang, Y. M., Dahler, G., Scott, K. J., 1988. Plant Sci., 57: 225-233.

[9] Murashige, T., Skoog, F., 1962. Physiol. Plant., 15: 473-497.

[10] Bommineni, V. R., Jauhar, P. P., 1996. Plant Sci., 116: 197-203.

[11] Linsmaier, E. M., Skoog, F., 1965. Physiol. Plant., 18: 100-126.

[12] Sági, F., Beke, B., Sági, L., 1990. In "Biotechnology in Agriculture and Forestry 13. Wheat." (ed. by Bajaj Y. P. S.) p. 494-510, SpringerVerlag, Berlin, Heidelberg, New York, Tokyo.

[13] McElroy, D., Zang, W., Cao, J., Wu, R., 1990. Plant Cell, 2: 163-171.

[14] Cao, J., Duan, X., McElroy, D., Wu, R., 1992. Plant Cell Rep., 11: 586-591.

[15] Takumi, S., Otani, M., Shimada, T., 1994. Plant Sci., 103: 161-166.

[16] Maniatis, T., Fitsch, E. F., Sambrook, J., 1982. In "Molecular Cloning: A laboratory Manual." Cold Spring Harbor Laboratory, New York.

[17] Mettler, I. J., 1987. Plant Mol. Biol. Rep., 5: 346 -349 .

[18] Liu, Y. G., Mori, N., Tsunewaki, K., 1990. Jpn. J. Genet., 65: 367-380.

[19] Shimada, T., 1978. Jpn. J. Genet., 53: 371-374.

[20] Mathias, R. J., Simpson, E. S., 1986. Plant Cell 
Tiss. \& Org. Cult., 7: 31-37.

[21] Carman, J. G., Jefferson, N. E., Campbell, W. F., 1987. Plant Cell Tiss. \& Org. Cult., 10: 101-113.

[22] Scott, K. J., He, D. G., Yang, Y. M., 1990. In "Biotechnology in Agriculture and Forestry 13. Wheat." (ed. by Bajaj, Y. P. S.), p. 46-67, Sprin-
ger-Verlag, Berlin, Heidelberg, New York, Tokyo.

[23] Takumi, S., Shimada, T., 1997. Genes Genet. Syst., 72: 63-69.

[24] Altpeter, F., Vasil, V., Srivastava, V., Stöger, E., Vasil, I. K., 1996. Plant Cell Rep., 16: 12-17. 